\title{
The Significance of the Continuous Murmurs in the Lutembacher Syndrome
}

\author{
Ken-chi Asano, M.D., Masahiko Washio, M.D., \\ and Kunio Hoshino, M.D.
}

\begin{abstract}
SUMMARY
It is enunciated that the Lutembacher syndrome can be approved of not only the atrial septal defect associated with the mitral stenosis but the mitral stenosis with secondary occurred or enlarged interatrial communication due to the left atrial hypertension. Moreover, the mechanism of the continuous murmurs occasionally heard at the lower sternal border is discussed from the present case and cases collected from the literatures. Successful surgical treatment of a patient with the Lutembacher syndrome in the above-mentioned concept is presented.
\end{abstract}

\section{Additional Indexing Words:}

Lutembacher syndrome Atriel septal defect Mitral stenosis Continuous murmurs

$\mathrm{T}$ HE Lutembacher syndrome has been defined as the atrial septal defect associated with the congenital or acquired mitral stenosis. Although the atrial septal defect and the mitral stenosis, excluding the congenital mitral stenosis, are very frequently encountered, this combination has been rarely reported. In the Niigata University Hospital only one case (the present case) was experienced among 442 surgical cases, including 120 cases of the atrial septal defect and 80 cases of the acquired mitral stenosis. The purpose of this article is to describe the successful surgery of a case with the mitral stenosis with a small foramen ovale defect, characterized by the continuous murmurs at the lower sternal border, and to discuss the broadened concept of the Lutembacher syndrome and the significance of the continuous murmurs.

\section{Case Report}

A 30-year-old Japanese wife who had not been diagnosed previously as the heart disease or the rheumatic fever, complained of progressive dyspnea and palpitation on exertion after the age of 26 . Cyanosis had not been found, but slight edema had appeared on her face at menstruation periods.

From the Department of Thoracic and Cardiovascular Surgery, Faculty of Medicine, University of Niigata, Niigata.

Received for publication November 1, 1967. 
On physical examination, the pulse was regular and its rate was 76 per min. Neither the chest deformity nor the thrills were found. The apical first sound was loud and the second sound was splitted and fixed with $\mathrm{P}_{2}$ accentuation. A slight diastolic rumble was heard at the apex, but the opening snap was faint. The ejection-type systolic murmurs $(3 / 6)$ at the 2nd intercostal space along the left sternal border, and in addition the continuous murmurs $(3 / 6)$ at bilateral lower sternal borders were heard (Fig. 1).

The chest X-ray films revealed the moderate cardiomegaly with the enlarge-

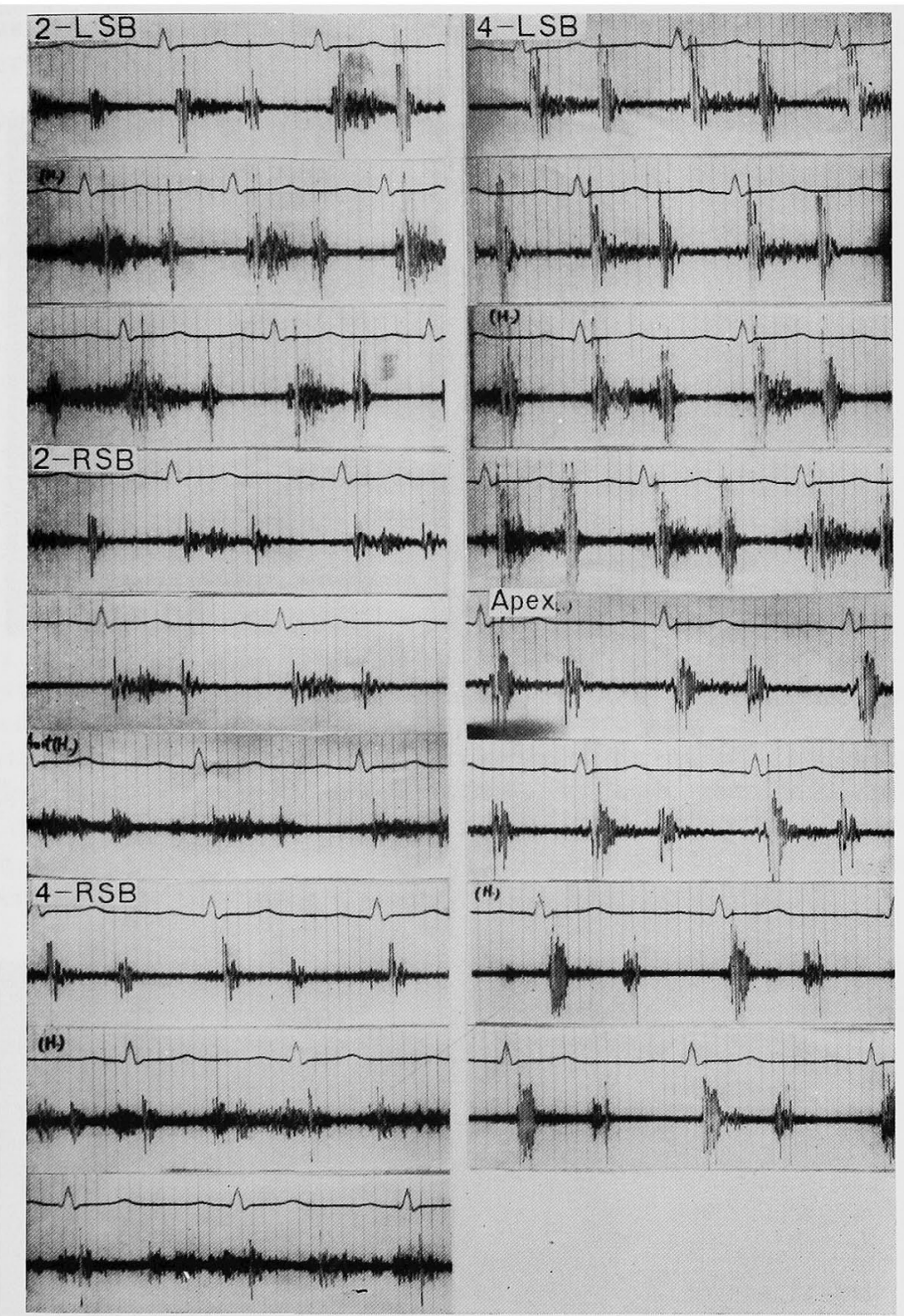

Fig. 1. The preoperative phonocardiogram. Intervals of Q-I and II-OS suggest the presence of the tight mitral stenosis. 
ment of both atria and the pulmonary trunk (Fig. 2). The electrocardiograms demonstrated the sinus rhythm, the right axis deviation, the left atrial enlargement and the right ventricular hypertrophy with the incomplete right bundle branch block (Fig. 3). On blood examinations, the hemoglobin was $13.8 \mathrm{Gm} . / 100 \mathrm{ml}$., red cell count was $550 \times 10^{4}$ and the hematocrit was 43.5 per cent. The C-reactive protein and the serum luetic reaction were negative, and the antistreptolysin titer was 125 units. No abnormalties were found in serum electrolytes and renal and liver function tests.

The right heart catheterization revealed the severe pulmonary hypertension with high pulmonary wedge pressure suggesting the left atrial hypertension and the

a

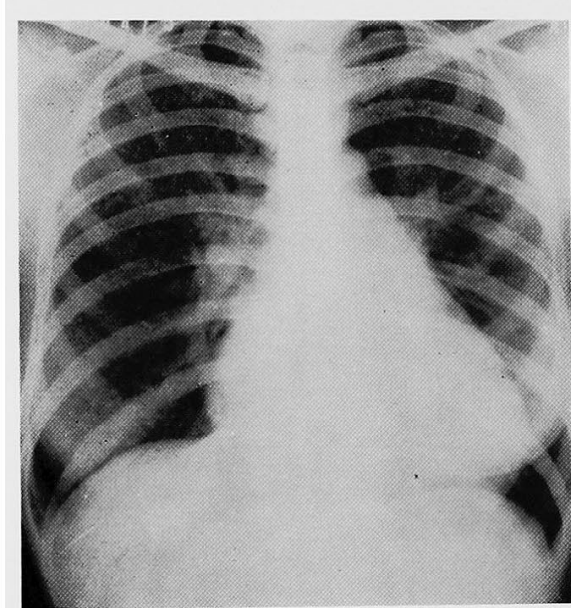

Fig. 2. The preoperative chest X-ray films. The moderate cardiomegaly (cardiothoracic ratio-61\%) and enlargement of both atria and the pulmonary trunk are demonstrated. b

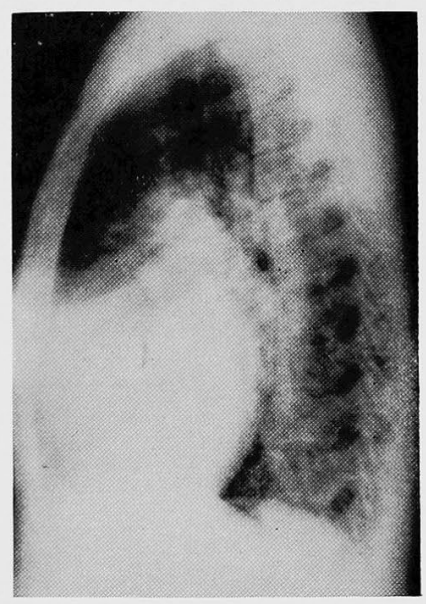

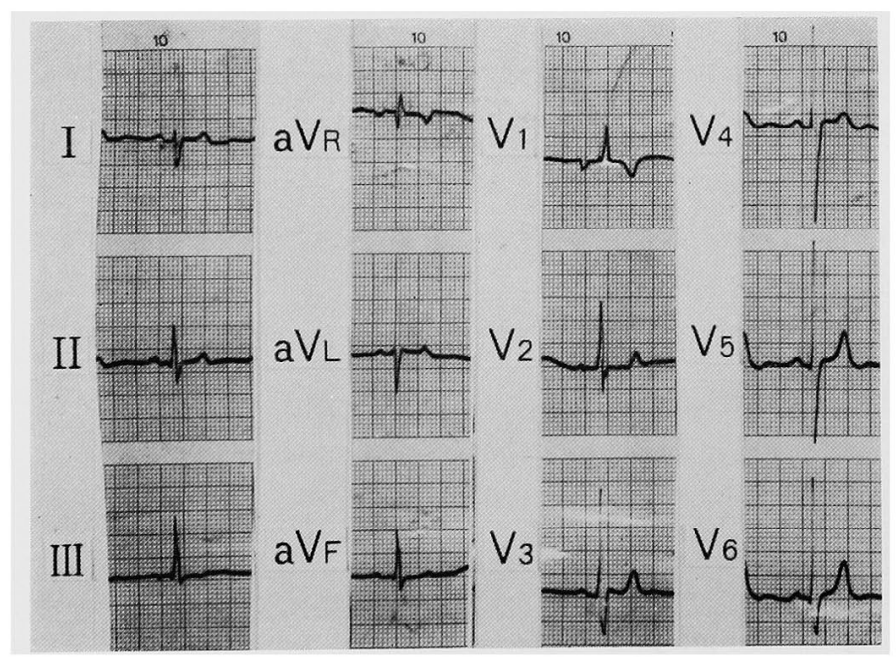

Fig. 3. The preoperative electrocardiograms. 
Table I. Right Heart Catheterization Data

\begin{tabular}{l|cc|c}
\multicolumn{1}{c|}{ Site } & Pressure in mm.Hg (mean) & O $_{2}$-content in Vol. \% \\
\hline Pulmonary wedge & $99 / 40$ & $(28.5)$ & \\
Pulmonary artery & $108 / 4$ & $(62.5)$ & 15.40 \\
Right ventricle & & $(47.5)$ & 15.20 \\
Right atrium & & $(12)$ & 14.95 \\
Superior vena cava & $128 / 74$ & & 12.85 \\
Femoral artery & & 17.40 \\
\hline Oxygen capacity & & 18.10 \\
\hline Oxygen consumption & & $215 \mathrm{ml} . / \mathrm{min}$. \\
\hline Body surface area & & $1.3 \mathrm{M} .^{2}$ \\
\hline
\end{tabular}

Systemic flow : $4.7 \mathrm{~L} . / \mathrm{min}$.

Pulmonary flow: $10.1 \mathrm{~L} . / \mathrm{min}$.

Effective pulmonary flow : $4.9 \mathrm{~L} . / \mathrm{min}$.

Pulmonary flow/Systemic flow : 2.2

Total pulmonary vascular resistance : 820 dynes $/ \mathrm{sec} . / \mathrm{cm} .^{-5}$

Pulmonary arteriolar resistance : 450 dynes $/ \mathrm{sec} . / \mathrm{cm}^{-5}$

Total peripheral resistance : 2,570 dynes $/ \mathrm{sec} . / \mathrm{cm}^{-5}$

left-to-right shunt at the atrial level (Table I). Under the diagnosis of the suspected Lutembacher syndrome with the small atrial defect, the open-heart surgery was performed on October 13, 1967.

At operation, continuous thrills were palpated on the wall of the dilated right atrium and the intra-atrial digital examination revealed a jet through a small opening of the atrial septum through which the operator's index finger could not be inserted into the left atrium. The right atriotomy under the cardiopulmonary by pass demonstrated a small foramen ovale defect sized $0.5 \mathrm{~cm}$. in diameter (Fig. 4).

Widening the defect by incision toward the inferior vena cava, the mitral valve was palpated. The orifice was $0.9 \mathrm{~cm} .{ }^{2}$ in area and demonstrated the tight stenosis. It was dilated by the Tubbs transventricular dilator to $37 \mathrm{~mm}$. in length without any sequential regurgitation. Then, the atrial septal defect and the right atrial wall were closed (Fig. 5). The mitral stenosis seemed the acquired.

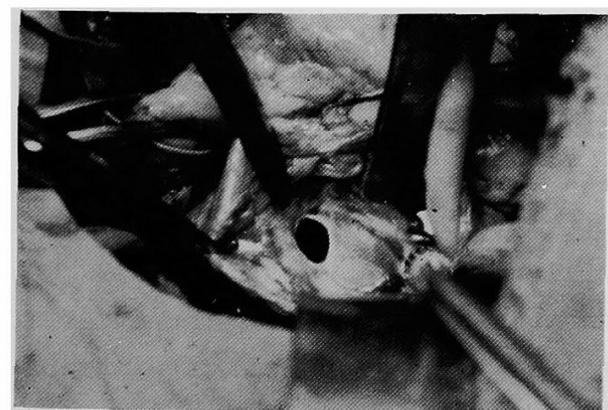

Fig. 4. Operative findings. A small foramen ovale defect is demonstrated.

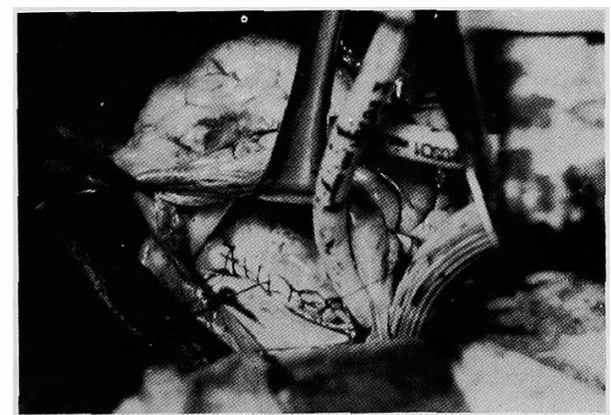

Fig. 5. Operative findings. The interatrial communication is closed. 


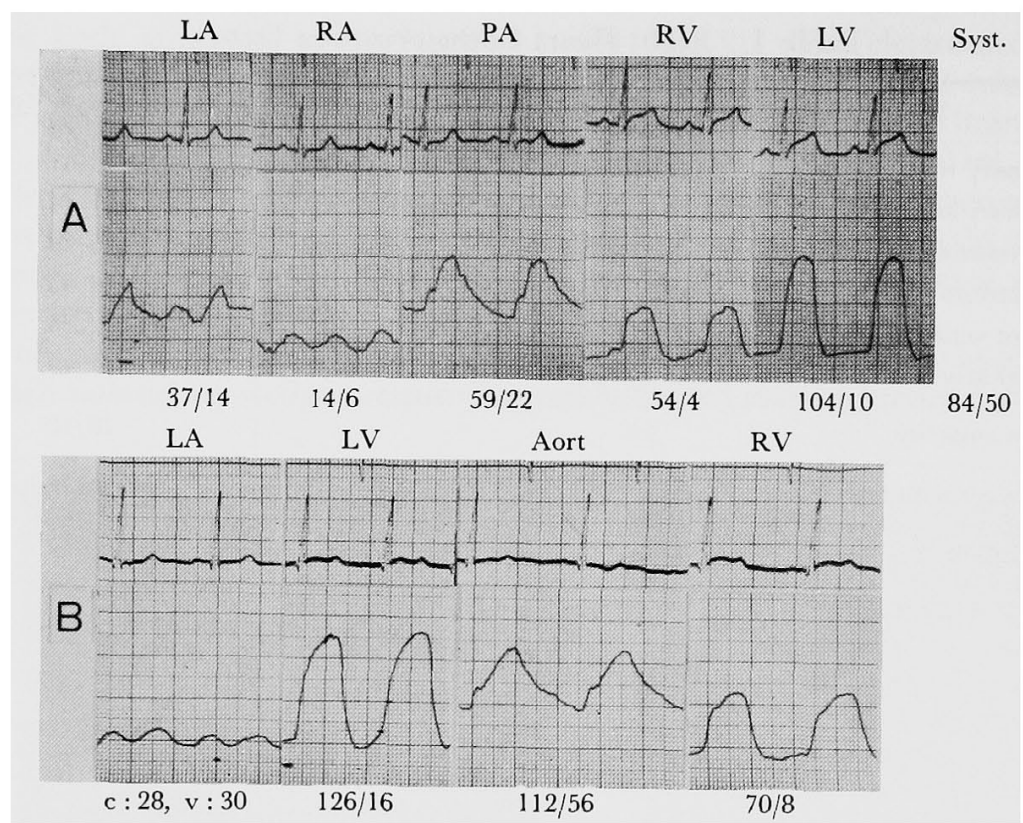

Fig. 6. The intracardiac pressure measurements during surgery. A: Datas before the procedure. B: Datas after the procedure. In A, the " $\mathrm{v}$ " wave is higher than the " $c$ " wave although the mitral regurgitation is not associated and the end-diastolic pressure gradient at the mitral level is $8 \mathrm{~mm}$. In $\mathrm{B}$, the end-diastolic pressure gradient at the mitral level is subsided.

Intra-cardiac pressure measurements were performed during surgery. The marked pressure gradient between both atria and the moderate end-diastolic pressure gradient uncorresponded with such tight stenosis at the mitral level were demonstrated before the cardiac procedure, and the latter was completely subsided after the procedure (Fig. 6). Her postoperative course was uneventful and discharged 18 days after the operation.

\section{Discussion}

The clinical features of the Lutembacher syndrome seem to be satisfactorily explained by the description of Espino-Vela ${ }^{11}$ as follows : Physically, (1) atypical auscultatory findings of rheumatic mitral stenosis; (2) the common presence of a systolic murmur accompanied by a palpable thrill in the pulmonary area; (3) cyanosis of slight to moderate degree in the heart failure. Radiologically, (1) the large size of the pulmonary main trunk and its branches, with (2) vigorous pulsations, in association with (3) a mitral or mitral-tricuspid cardiac contour, and (4) slight or absent left atrial enlargement. Electrocardiographically, (1) the presence of RBBB and (2) commonly, qR type complexes in $\mathrm{V}_{4}$ with (3) concomitant left atrial enlargement (mitral-P wave). 
And moreover, he indicated that the clinical features were similar to the atrial septal defect when the interatrial communication was large, and contrarily to the mitral stenosis when the communication was small.

The hemodynamic significance or interest about the Lutembacher syndrome is on the left atrial pressure which should be fundamentally elevated due to the mitral stenosis, to be decompressed by the associated interatrial communication, as indicated by Taussig. ${ }^{2)}$ The decompression of the left atrial hypertension represented by the Lutembacher syndrome, has been interested and studied even on the congenital mitral atresia or the acquired mitral regurgitation associated with the interatrial communication. ${ }^{3)-5)}$ Hitherto, this syndrome has been defined as the congenital atrial septal defect incidentally associated with the congenital or acquired mitral stenosis, but adding to this classic definition, there is recently a tendency to accept the status in which the very small atrial septal defect or the functionally closed foramen ovale was secondarily enlarged and signified hemodynamically by stretching of the left atrium due to the primarily presented mitral stenosis, as the broadened concept of the Lutembacher syndrome. ${ }^{5)}$ However, the authors think

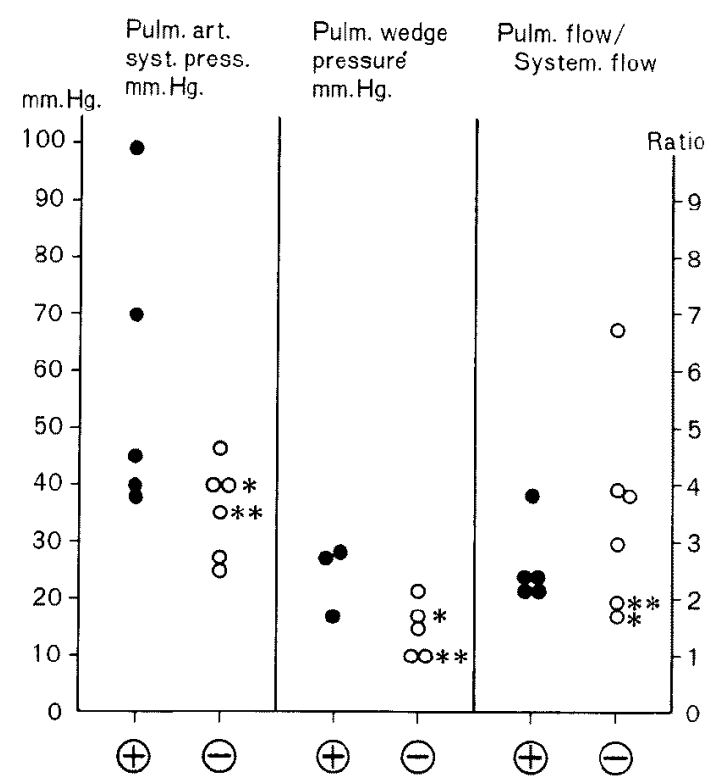

Fig. 7. The relationship between the presence of the continuous murmurs and the hemodynamics.

$($-Case with the continuous murmurs

$\Theta$-Gase without the continuous murmurs

*-Thrills are palpated on the right atrial wall

**-The tricuspid stenosis is associated 


\begin{tabular}{|c|c|c|c|c|c|c|c|c|c|c|c|c|}
\hline 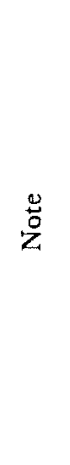 & 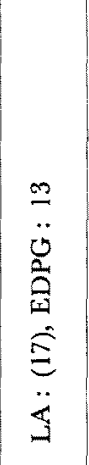 & & 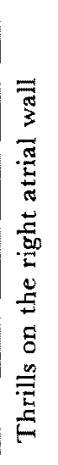 & 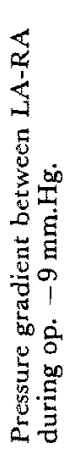 & & 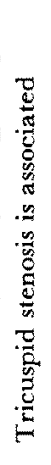 & 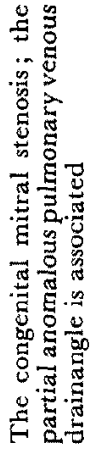 & & & 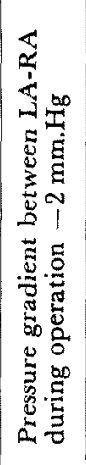 & $\begin{array}{l}\infty \\
\vdots \\
\vdots \\
01\end{array}$ & \\
\hline$\sum_{\Sigma}^{\infty}$ & हैं & + & $\stackrel{\text { घี่ }}{-}$ & 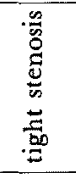 & 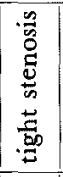 & हृ่ & 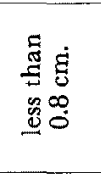 & 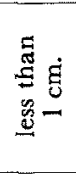 & $\frac{\text { a }}{\mathrm{g}}$ & 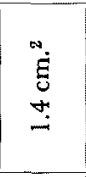 & $\begin{array}{l}\stackrel{3}{8} \\
\text { gु } \\
8 \\
0\end{array}$ & \\
\hline 是 & 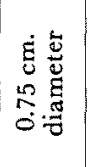 & $\begin{array}{l}\dot{g} \\
0 \\
0 \\
\dot{0} \\
x \\
-\end{array}$ & 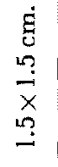 & $\begin{array}{l}\dot{g} \\
0 \\
0 \\
\times \\
\infty\end{array}$ & $\dot{\xi}$ & 㺃 & 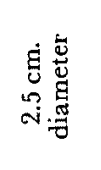 & 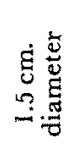 & 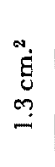 & 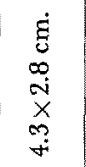 & 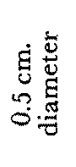 & \\
\hline 总魚 & + & + & 1 & 1 & +1 & 1 & 1 & 1 & + & 1 & + & - \\
\hline $\begin{array}{l}\alpha \\
\alpha \\
\alpha\end{array}$ & $\dot{i}$ & $\ddot{n}$ & $\because$ & $\ddot{m}$ & $\infty$ & $\stackrel{9}{-}$ & $\stackrel{\infty}{m}$ & i & $\stackrel{\sim}{\sim}$ & $\hat{0}$ & $\stackrel{\sim}{\sim}$ & 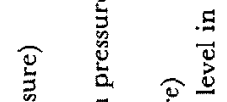 \\
\hline 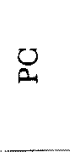 & & & 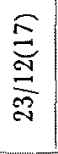 & $\hat{\varrho}$ & $\Xi$ & $\stackrel{\varrho}{\varrho}$ & $\stackrel{\widehat{s}}{\mathrm{~g}}$ & $\widehat{\widehat{্}}$ & $\frac{\widehat{a}}{\frac{d}{d}}$ & & กุ & 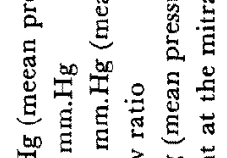 \\
\hline$\overleftrightarrow{\omega}$ & $\frac{2}{\frac{9}{q}}$ & $\frac{\mathscr{2}}{\frac{9}{9}}$ & $\frac{\stackrel{\Delta}{\sigma}}{\sigma}$ & $\stackrel{\varrho}{\frac{9}{q}}$ & $\stackrel{\infty}{\bar{\infty}}$ & $\underset{m}{\stackrel{ \pm}{m}}$ & 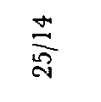 & $\frac{\text { sิ }}{6}$ & $\frac{\mathfrak{m}}{\frac{N}{R}}$ & $\stackrel{\infty}{\stackrel{N}{N}}$ & $\frac{8}{\infty}$ & 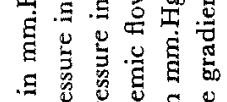 \\
\hline 幽 & E & (อ) & 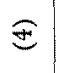 & $\approx$ & 6 & $\widehat{\mathscr{C}}$ & $\widehat{E}$ & $\widehat{a}$ & & & $\stackrel{a}{=}$ & 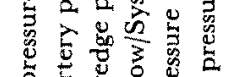 \\
\hline 免 & is & 5 & 5 & 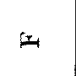 & 5 & H & 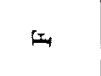 & 战 & 匠 & $\Sigma$ & Fis & 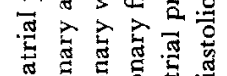 \\
\hline$\stackrel{心}{\longleftarrow}$ & $\mathscr{m}$ & $\mathscr{q}$ & ল & F & $\vec{N}$ & $F$ & స్ & $\vec{m}$ & : & $\Omega$ & 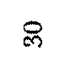 & 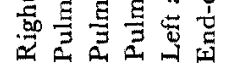 \\
\hline 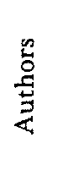 & 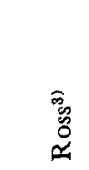 & & 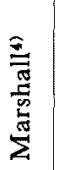 & & 恶 & & 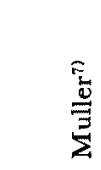 & & & 焉 & 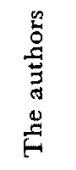 & 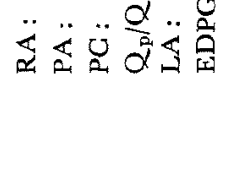 \\
\hline
\end{tabular}


that all types of the left atrial decompression should not be included into this syndrome and this must be limited to the combination of the interatrial communication and the mitral stenosis in reference to Lutembacher's original description.

The second interesting finding is the continuous murmurs which have not been described in the classic Lutembacher syndrome. The continuous murmurs were heard at the lower sternal border and were reported occasionally in cases with small interatrial communication. ${ }^{3,55,6)}$ Ross indicated that the continuous murmurs were augmented by inspiration and reduced or abolished by the Valsalva maneuver. ${ }^{3)}$

The authors studied the mechanism of this murmur hemodynamically from the present case and cases collected from the literatures. ${ }^{3-7)}$ of 11 patients examined by right heart catheterizations, the continuous murmurs were heard in 5 cases and they demonstrated common clinical features and operating findings similar to the present case. Fig. 7 and Table II show the relationship between the presence of continuous murmurs and results of right heart catheterizations. Both the pulmonary systolic pressures and the pulmonary wedge pressures are higher in cases with the continuous murmurs, and the left-to-right shunts are rather small in them. Annotating in Fig. 7, these tendencies will be more pronounced if the case with the tricuspid stenosis is excluded for the reason that the effect of the left atrial decompression through the interatrial communication may be disturbed by this added anomaly. On the other hand, sizes of the communication are all less than $1.5 \mathrm{~cm}$. in diameter in cases with the continuous murmurs and contrarily, more than $1.5 \mathrm{~cm}$. in diameter in all other cases without the continuous murmurs except the case with the tricuspid stenosis (Table II). From above-mentioned findings, it seems to be definite that the occurrence of this characteristic murmur needs the marked pressure gradient between both atria, and in such cases the mitral stenosis play the leading role in clinical features.

\section{REFERENCES}

1. Espino-Vela, J.: Am. Heart J. 57: 185, 1959.

2. Taussig, H. B.: Congenital Malformations of the Heart (2nd ed.), Harvard Univ. Press, 1960.

3. Ross, J., Jr., Braunwald, E., Mason, D. T., Braunwald, N. S., and Morrow, A. G. : Circulation $28: 853,1963$.

4. Marshall, R. J. and Warden, H. E. : Circulation 29:432, 1964.

5. Goldfarb, B. and Wang, Y.: Am. J. Cardiol. 17: 319, 1966.

6. Furuta, S.: Shinryo 14: 1412, 1961 (in Japanese).

7. Muller, W. H., Jr., Littlefield, J. B., and Beckwitch, J. R. : J. Thorac. Cardiovas. Surg. 51 : $66,1966$. 